Relations industrielles

Industrial Relations

\title{
Work in American Society, by Seymour Wolfbein, Scott, Foresman Series in Institutions and Modern Social Problems, Glenview, Illinois, Scott, Foresman \& Co., 1971, 195 pp.
}

\section{Bertrand Belzile}

Volume 28, numéro 4, 1973

URI : https://id.erudit.org/iderudit/028457ar

DOI : https://doi.org/10.7202/028457ar

Aller au sommaire du numéro

Éditeur(s)

Département des relations industrielles de l'Université Laval

ISSN

0034-379X (imprimé)

1703-8138 (numérique)

Découvrir la revue

Citer ce compte rendu

Belzile, B. (1973). Compte rendu de [Work in American Society, by Seymour Wolfbein, Scott, Foresman Series in Institutions and Modern Social Problems, Glenview, Illinois, Scott, Foresman \& Co., 1971, 195 pp.] Relations industrielles / Industrial Relations, 28(4), 884-884. https://doi.org/10.7202/028457ar

Tous droits réservés ㄷ Département des relations industrielles de l'Université Laval, 1973
Ce document est protégé par la loi sur le droit d'auteur. L’utilisation des services d'Érudit (y compris la reproduction) est assujettie à sa politique d'utilisation que vous pouvez consulter en ligne.

https://apropos.erudit.org/fr/usagers/politique-dutilisation/ 


\section{RECENSIONS}

Work in American Society, by Seymour Wolfbein, Scott, Foresman Series in Institutions and Modern Social Problems, Glenview, Illinois, Scott, Foresman \& Co., 1971, $195 \mathrm{pp}$.

Ce livre présente un très vif intérêt à plusieurs égards. D'abord, il traite d'un sujet de grande actualité. Ensuite, il est d'un accès facile à quiconque sait lire. Enfin, il est écrit dans un excellent style et avec une clarté impressionnante. Somme toute, son auteur est un vulgarisateur extraordinaire, lequel d'ailleurs n'en est pas à ses premières armes.

Le livre se divise en deux parties assez distinctes l'une de l'autre. Dans une première, Wolfbein décrit la nature du travail et les conditions de travail qui prévalent aux Etats-Unis depuis quelques années: ce qu'est le travailleur américain; les profils de la population active avec un accent sur les changements qui s'y produisent; l'impact de la technologie industrielle; les relations entre l'occupation et l'éducation; et le problème du chômage en relation avec celui de la pauvreté. Naturellement, toute description tend à être fastidieuse : le lecteur se voit confronté avec une multitude de données, statistiques et autres. La lecture de cette première partie est affectée en partie par cette tendance. Heureusement, le lecteur peu averti, dans le domaine du travail, y trouvera plusieurs explications fort intéressantes et retirera donc un bon profit en y investissant quelques heures.

Quant à la deuxième partie, elle présente certes un intérêt plus grand. L'auteur $\mathrm{y}$ fait une heureuse synthèse des efforts tentés par les américains pour solutionner les problèmes du travail qui apparaissent ici et là dans la première partie. Ces efforts sont regroupés sous trois têtes de chapitre : la politique économique, la politique de main-d'œuvre et la politique de soutien du revenu. L'auteur fait bien ressortir les relations de dépendance qui existent entre ces trois politiques.

La politique économique vise ici principalement l'objectif du plein emploi. Wolfbein note en passant les aspects ori- ginaux de celle-ci, par exemple la réduction de taxes de 1964, laquelle allait à l'encontre de la théorie fiscale qui prévalait à l'époque. Il souligne aussi l'originalité, pour les Etats-Unis du moins, de la politique de revenus (les fameux "guidelines »), sans oublier l'intervention accrue de l'Etat dans plusieurs champs d'activité économique.

Dans le domaine de la politique de main-d'œuvre, l'auteur fait bien ressortir aussi le coup de barre qui a été donné aux Etats-Unis au cours des années 1960, surtout à partir de 1962 avec le «Manpower Development and Training Act». La liste des programmes de main-d'œuvre est très longue et les sommes impliquées dans ces programmes sont très élevées.

Bien sûr, malgré l'existence de politiques économique et de main-d'œuvre, il se trouve un certain nombre de personnes qui ne peuvent pas vivre de leur travail. Des programmes de soutien du revenu permettent à celles-ci de subvenir à leurs besoins essentiels. Et Wolfbein indique avec à-propos que l'opinion publique américaine a considérablement évolué depuis quelques années et il prévoit que cette évolution se continuera dans l'avenir. Encore une fois, l'intérêt de cette partie, provient non seulement de l'excellente synthèse qu'y fait l'auteur des politiques mentionnées ci-dessus, mais aussi du fait que l'auteur fait bien comprendre au lecteur que toutes les politiques sont fortement interdépendantes.

Université Laval

\section{Bertrand BELZILE}

Workers' Management and Workers' Wages in Yugoslavia - The Theory and Practice of Participatory Socialism, by Howard $M$. Wachtel, Ithaca and London, Cornell University Press, 1973 (XII - 220, bibl., index).

Ce volume prendra place parmi les études partielles mais importantes du régime yougoslave de gestion collective des entreprises. L'auteur situe d'abord ce régime et son analyse dans un cadre 